\title{
Clinical significance of high-dose cytarabine added to cyclophosphamide/total-body irradiation in bone marrow or peripheral blood stem cell transplantation for myeloid malignancy
}

Yasuyuki Arai ${ }^{1}$, Kazunari Aoki ${ }^{1}$, June Takeda ${ }^{1}$, Tadakazu Kondo ${ }^{1 *}$, Tetsuya Eto ${ }^{2}$, Shuichi Ota ${ }^{3}$, Hisako Hashimoto ${ }^{4}$, Takahiro Fukuda ${ }^{5}$, Yukiyasu Ozawa ${ }^{6}$, Yoshinobu Kanda ${ }^{7}$, Chiaki Kato ${ }^{8}$, Mineo Kurokawa ${ }^{9}$, Koji Iwato ${ }^{10}$, Makoto Onizuka ${ }^{11}$, Tatsuo Ichinohe ${ }^{12}$, Yoshiko Atsuta ${ }^{13,14}$, Akiyoshi Takami ${ }^{15}$ and on behalf of the AML and MDS Working Group of the Japan Society for Hematopoietic Cell Transplantation

\begin{abstract}
Background: Addition of high-dose cytarabine (HDCA) to the conventional cyclophosphamide/total-body irradiation (CY/TBI) regimen significantly improved prognosis after cord blood transplantation (CBT) for adult acute myelogenous leukemia (AML) and myelodysplastic syndrome (MDS). The efficacy of HDCA in bone marrow or peripheral blood stem cell transplantation (BMT/PBSCT), however, has not yet been elucidated.
\end{abstract}

Findings: We conducted a cohort study to compare the prognosis of HDCA/CY/TBI $(N=435)$ and $C Y / T B I(N=1667)$ in BMT/PBSCT for AML/MDS using a Japanese transplant registry database. The median age was 38 years, and $86.0 \%$ of the patients had AML. Unrelated donors comprised $54.6 \%$, and $63.9 \%$ of donors were human leukocyte antigen (HLA)-matched. Overall survival (OS) was not improved in the HDCA/CY/TBI group (adjusted hazard ratio (HR), $1.14 ; p=0.13)$. Neutrophil engraftment was inferior $(H R, 0.80 ; p<0.01)$, and the incidence of hemorrhagic cystitis and thrombotic microangiopathy increased in $\mathrm{HDCA} / \mathrm{CY} / \mathrm{TBI}(\mathrm{HR}, 1.47$ and 1.60; $p=0.06$ and 0.04 , respectively), leading to significantly higher non-relapse mortality (NRM; HR, 1.48; $p<0.01)$. Post-transplant relapse and tumor-related mortality were not suppressed by the addition of HDCA.

Conclusions: This study indicated the inefficacy of HDCA/CY/TBI in BMT/PBSCT for AML/MDS. Our results should be validated in large-scale prospective studies.

\section{Introduction}

Cyclophosphamide/total-body irradiation (CY/TBI) is a widely known conventional myeloablative regimen in allogeneic hematopoietic cell transplantation (HCT) for adult acute myelogenous leukemia (AML) and myelodysplastic syndrome (MDS) [1-3], while regimens with stronger anti-leukemic effects have been sought to reduce post-transplant relapse [4]. Among them, the

\footnotetext{
* Correspondence: tadakazu@kuhp.kyoto-u.ac.jp

'Department of Hematology and Oncology, Graduate School of Medicine, Kyoto University, 54, Shogoin Kawahara-cho, Sakyo-ku, Kyoto 606-8507, Japan Full list of author information is available at the end of the article
}

addition of high-dose cytarabine (HDCA) to CY/TBI may be promising; in our recent large-scale study, HDCA/CY/TBI significantly improved overall survival (OS) compared to CY/TBI by suppressing relapse without increasing severe adverse events or non-relapse mortality (NRM) in cord blood transplantation (CBT) for AML/MDS [5]. However, previous studies in a small cohort with mixed hematopoietic malignancies showed that HDCA/CY/TBI increased NRM after bone marrow transplantation (BMT) [6, 7]. These results require validation using disease-specified and newer cohorts, in order to reflect the characteristics of each malignancy and the 
Table 1 Patient characteristics

\begin{tabular}{|c|c|c|c|c|c|c|c|c|}
\hline \multirow[t]{2}{*}{ Variables } & & \multicolumn{2}{|l|}{ Total } & \multicolumn{2}{|l|}{$\mathrm{CY} / \mathrm{TBI}$} & \multicolumn{2}{|c|}{$\mathrm{HDCA} / \mathrm{CY} / \mathrm{TBI}$} & \multirow[b]{2}{*}{$p$} \\
\hline & & $N=2102$ & $\%$ & $N=1667$ & $\%$ & $N=435$ & $\%$ & \\
\hline \multirow[t]{2}{*}{ Sex } & Male & 1205 & 57.3 & 959 & 57.5 & 246 & 56.5 & \\
\hline & Female & 897 & 42.7 & 708 & 42.5 & 189 & 43.5 & 0.71 \\
\hline \multirow[t]{4}{*}{ Age } & Median (years) & 38 & & 38 & & 38 & & 0.10 \\
\hline & (Range) & \multicolumn{2}{|c|}{$(16-64)$} & \multicolumn{2}{|c|}{$(16-62)$} & \multicolumn{2}{|c|}{$(16-64)$} & \\
\hline & $\leq 49$ & 1762 & 83.8 & 1391 & 83.4 & 371 & 85.3 & \\
\hline & $\geq 50$ & 340 & 16.2 & 276 & 16.6 & 64 & 14.7 & 0.35 \\
\hline \multirow[t]{3}{*}{ PS } & $0-1$ & 1963 & 93.3 & 1577 & 94.6 & 386 & 88.7 & \\
\hline & $\geq 2$ & 104 & 5.0 & 62 & 3.7 & 42 & 9.7 & \\
\hline & Unknown & 35 & 1.7 & 28 & 1.7 & 7 & 1.6 & $<0.01^{*}$ \\
\hline \multirow[t]{3}{*}{$\mathrm{HCT}-\mathrm{Cl}$} & $\leq 2$ & 1287 & 61.2 & 1024 & 61.4 & 263 & 60.5 & \\
\hline & $\geq 3$ & 111 & 5.3 & 90 & 5.4 & 21 & 4.8 & \\
\hline & Unknown & 704 & 33.5 & 553 & 33.2 & 151 & 34.7 & 0.78 \\
\hline \multirow[t]{3}{*}{ CMV sero-status } & Negative & 392 & 18.7 & 312 & 18.7 & 80 & 18.4 & \\
\hline & Positive & 1524 & 72.4 & 1221 & 73.3 & 303 & 69.6 & \\
\hline & Unknown & 186 & 8.9 & 134 & 8.0 & 52 & 12.0 & $0.04^{*}$ \\
\hline \multirow[t]{2}{*}{ Diagnosis } & AML & 1808 & 86.0 & 1397 & 83.8 & 411 & 94.5 & \\
\hline & MDS & 294 & 14.0 & 270 & 16.2 & 24 & 5.5 & $<0.01^{*}$ \\
\hline \multirow[t]{2}{*}{ Disease risk } & Standard & 1276 & 60.7 & 1074 & 64.4 & 202 & 46.4 & \\
\hline & High & 826 & 39.3 & 593 & 35.6 & 233 & 53.6 & $<0.01^{*}$ \\
\hline \multirow[t]{2}{*}{ (In AML) } & Standard & 1191 & 65.9 & 993 & 71.1 & 198 & 48.2 & \\
\hline & High & 617 & 34.1 & 404 & 28.9 & 213 & 51.8 & $<0.01^{*}$ \\
\hline \multirow[t]{2}{*}{ (In MDS) } & Standard & 85 & 28.9 & 81 & 30.0 & 4 & 16.7 & \\
\hline & High & 209 & 71.1 & 189 & 70.0 & 20 & 83.3 & 0.17 \\
\hline \multirow[t]{3}{*}{ Days from diagnosis to $\mathrm{HCT}$} & Median & 239 & & 240 & & 237 & & $0.03^{*}$ \\
\hline & $\leq 240$ & 1056 & 50.2 & 834 & 50.0 & 222 & 51.0 & \\
\hline & $\geq 241$ & 1046 & 49.8 & 833 & 50.0 & 213 & 49.0 & 0.71 \\
\hline \multirow[t]{3}{*}{ Donor source } & Rel-BM & 455 & 21.7 & 351 & 21.1 & 104 & 23.9 & \\
\hline & Rel-PB & 499 & 23.7 & 386 & 23.2 & 113 & 26.0 & \\
\hline & UR-BM & 1148 & 54.6 & 930 & 55.7 & 218 & 50.1 & 0.11 \\
\hline \multirow[t]{2}{*}{ Graft cell dose } & BM (NCC, median) & \multicolumn{2}{|c|}{$2.69 \times 10^{8} / \mathrm{kg}$} & \multicolumn{2}{|c|}{$2.66 \times 10^{8} / \mathrm{kg}$} & \multicolumn{2}{|c|}{$2.77 \times 10^{8} / \mathrm{kg}$} & 0.27 \\
\hline & PB (CD34 $4^{+}$cell count, median) & $3.99 \times 1$ & & $4.00 x$ & & $3.67 x$ & /kg & 0.52 \\
\hline HLA mismatch & Matched & 1343 & 63.9 & 1057 & 63.4 & 286 & 65.7 & \\
\hline & Mismatched & 759 & 36.1 & 610 & 36.6 & 149 & 34.3 & 0.37 \\
\hline Sex mismatch & Matched & 1145 & 54.4 & 919 & 55.1 & 226 & 51.9 & \\
\hline & $\mathrm{M}$ to $\mathrm{F}$ & 508 & 24.2 & 398 & 23.9 & 110 & 25.3 & \\
\hline & $\mathrm{F}$ to $\mathrm{M}$ & 445 & 21.2 & 346 & 20.8 & 99 & 22.8 & \\
\hline & Unknown & 4 & 0.2 & 4 & 0.2 & 0 & 0.0 & 0.45 \\
\hline ABO mismatch & Matched & 1114 & 53.0 & 888 & 53.3 & 226 & 52.0 & \\
\hline & Minor & 389 & 18.5 & 305 & 18.3 & 84 & 19.3 & \\
\hline & Major & 354 & 16.8 & 287 & 17.2 & 67 & 15.4 & \\
\hline & Both & 186 & 8.9 & 148 & 8.9 & 38 & 8.7 & \\
\hline & Unknown & 59 & 2.8 & 39 & 2.3 & 20 & 4.6 & 0.12 \\
\hline
\end{tabular}


Table 1 Patient characteristics (Continued)

\begin{tabular}{|c|c|c|c|c|c|c|c|c|}
\hline \multirow[t]{2}{*}{ GVHD prophylaxis } & CyA based & 1033 & 49.1 & 816 & 49.0 & 217 & 49.9 & \\
\hline & Tac based & 1069 & 50.9 & 851 & 51.0 & 218 & 50.1 & 0.73 \\
\hline \multirow[t]{2}{*}{ Year of HCT } & $\leq 2008$ & 1107 & 52.7 & 875 & 52.5 & 232 & 53.3 & \\
\hline & $\geq 2009$ & 995 & 47.3 & 792 & 47.5 & 203 & 46.7 & 0.75 \\
\hline \multirow[t]{2}{*}{ Follow-up period } & Median & 1134 & & 1130 & & 1171.5 & & 0.11 \\
\hline & (Range) & \multicolumn{2}{|c|}{$(40-4947)$} & \multicolumn{2}{|c|}{$(40-4922)$} & \multicolumn{2}{|c|}{$(41-4947)$} & \\
\hline
\end{tabular}

$C Y$ cyclophosphamide, TBI total-body irradiation, HDCA high-dose cytarabine, PS performance status, $H C T$ - $C l$ hematopoietic cell transplant co-morbidity index, $C M V$ cytomegalovirus, $A M L$ acute myelogenous leukemia, MDS myelodysplastic syndrome, Rel related donor, UR unrelated donor, BM bone marrow graft, $P B$ peripheral blood stem cell graft, NCC nucleated cell count, $H L A$ human leukocyte antigen, $M$ to $F$ male to female, $F$ to $M$ female to male, GVHD graft-versus-host disease, CyA cyclosporine, Tac tacrolimus

*Indicates statistically significant by the $x^{2}$ test or Student's $t$ test

recent progress in supportive therapies, such as antibiotics. Therefore, we performed a cohort study to compare prognosis following HDCA/CY/TBI and CY/TBI in AML/MDS patients who underwent BMT or peripheral blood stem cell transplantation (PBSCT), using the Japanese transplant registry database.

\section{Patients and methods}

Data for adult patients (age $\geq 16$ years) with AML and MDS who underwent allogeneic BMT or PBSCT from related (Rel) or unrelated (UR) donors as first HCT after CY/ TBI (CY, total $120 \mathrm{mg} / \mathrm{kg}$; TBI, 10-12 Gy) or HDCA/CY/ TBI (CA, 2-3 g/m $\mathrm{m}^{2}$ twice a day for 2-3 days) [5] between January 1, 2000 and December 31, 2012, were obtained from the Japanese Transplant Registry Unified Management Program (TRUMP) [8]. UR-PBSCT and haploidentical HCT were not included because of the small number of patients. Donor-derived serum and/or erythrocytes were depleted from grafts in case of mismatched ABO blood type, and grafts were transplanted without $\mathrm{T}$ cell depletion. Our protocol complied with the Declaration of Helsinki, and it was approved by the TRUMP Data Management Committee and the Ethics Committee of Kyoto University. Each patient provided written informed consent.

From the registry database, we extracted data on basic pre-transplant characteristics and post-transplant clinical courses. Disease risk was defined as previously reported [9]. Disparity in human leukocyte antigen (HLA)-A, B, and DR antigens was determined at the serologic level in RelBMT and Rel-PBSCT. In UR-BMT, 8 antigens including HLA-C were determined at the allele level; a 6/6 (Rel) or 8/8 (UR) match was considered HLA-matched [10]. Statistical analyses were performed as described previously [5].

\section{Results}

We evaluated 2102 patients who underwent HCT with CY/TBI $(N=1667)$ or HDCA/CY/TBI $(N=435)$, with a median follow-up of 1134 days (range, 40-4947 days). Patients with AML and high-risk disease were conditioned more frequently with HDCA/CY/TBI (Table 1). The dose of TBI was not different between CY/TBI and
HDCA/CY/TBI (10 Gy, 4.5 vs $4.3 \%$; 12 Gy, 95.1 vs $94.3 \%$, respectively); 12 Gy was divided into 4 (26.1 vs $34.1 \%$ ) or 6 fractions (70.2 vs $60.9 \%$ ). Graft-versus-host disease (GVHD) prophylaxis composed of cyclosporine (49.1\%) or tacrolimus (50.9\%), most of which (more than $96 \%$ ) were combined with methotrexate. No difference was observed between the two groups.

OS of the HDCA/CY/TBI group was inferior to that of the CY/TBI group (Fig. 1a; 59.3 vs $72.0 \%$ at 1 year; 45.3 vs $58.8 \%$ at 3 years after $\mathrm{HCT}$ ). This difference was significant on univariate analysis (Table 2), but not on multivariate analysis after adjustment for confounding factors (hazard ratio (HR), $1.14 ; p=0.13$; Table 3 ). In subgroup analyses according to pre-transplant characteristics, OS in the HDCA/ $\mathrm{CY} / \mathrm{TBI}$ group was significantly inferior in standard-risk disease $(\mathrm{HR}, 1.52 ; p<0.01)$. No significant differences were found in other subgroups (Additional file 1: Figure S1).

Relapse, tumor-related mortality, and NRM were calculated; relapse was not reduced by HDCA addition (HR, 0.90; 95 \% confidence interval (CI), 0.63-1.30; $p=0.58)$, resulting in unmitigated tumor-related mortality in the HDCA/CY/TBI group (Fig. $1 \mathrm{~b}$ and Table 3) regardless of disease risk (high risk: HR, 0.91; $p=0.47$; standard risk: $\mathrm{HR}, 0.84 ; p=0.46)$. On the other hand, HDCA/CY/TBI significantly increased NRM in the whole cohort (HR, 1.48; $p<0.01$; Fig. $1 \mathrm{c}$ and Table 3) especially in the acute phase after HCT. The major causes of NRM included organ failure, infection, and GVHD, without significant differences between the two groups (Table 4).

We compared the clinical courses that led to higher NRM in HDCA/CY/TBI, with a focus of engraftment, GVHD, infection, and other acute phase complications (Fig. 2). The HDCA/CY/TBI group showed significantly lower proportions of neutrophil and platelet engraftment following HCT (HR, 0.80; $p<0.01$, and HR, 0.83; $p<0.01$, respectively). Complete chimerism was achieved in $78.2 \%$ of the CY/TBI group vs $72.6 \%$ of the HDCA/ CY/TBI group $(p=0.04)$. We observed no significant differences in the incidence of acute or chronic GVHD (grades II-IV acute GVHD, 39.3 vs 38.2 \%; chronic GVHD 

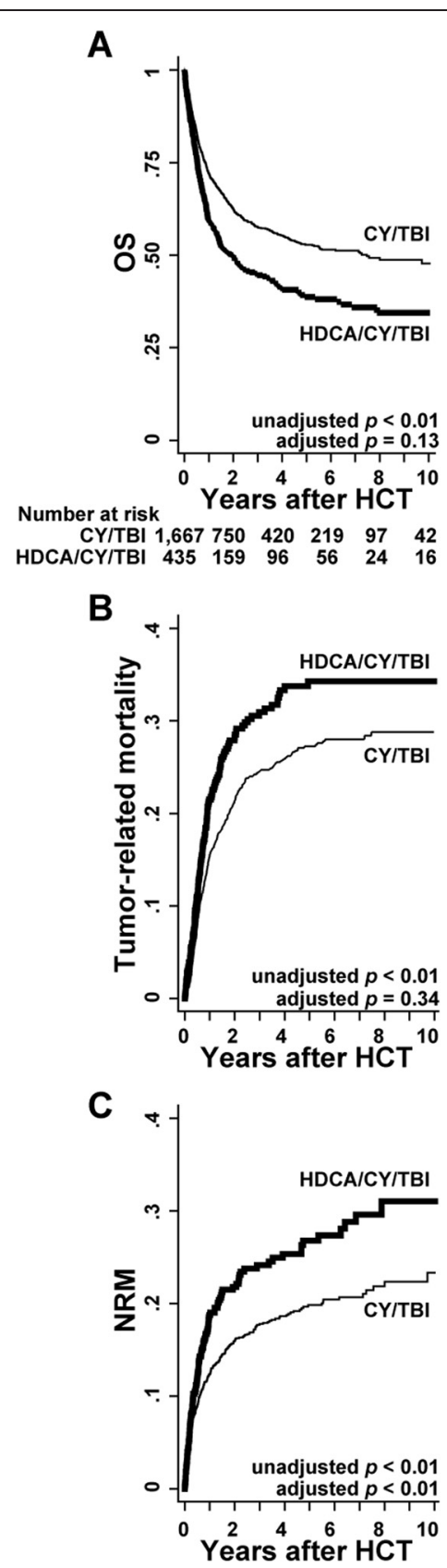

Fig. 1 Prognosis after HCT in each group of the conditioning regimen. a OS was calculated with the Kaplan-Meier method in each group of HDCA/CY/TBI and CY/TBI. HR for overall mortality of HDCA/CY/TBI compared to CY/TBI was calculated by Cox proportional hazards model after being adjusted for confounding factors such as patient sex, age, PS, CMV sero-status, diagnosis, disease risk, days from diagnosis to HCT, HLA mismatch, sex mismatch, and year of HCT. b Tumor-related mortality, defined as death without remission or after relapse, was calculated using Gray's method considering therapy-related death as a competing risk. HR was calculated by using Fine-Gray proportional hazards model adjusted by the confounding factors mentioned above. c NRM was calculated using Gray's method considering relapse as a competing risk. HR was also calculated using the same model
Table 2 Univariate analysis of prognosis

\begin{tabular}{|c|c|c|c|c|}
\hline \multirow[t]{2}{*}{ Variables } & & \multicolumn{2}{|c|}{ Overall mortality } & \multirow[b]{2}{*}{$p$} \\
\hline & & $\mathrm{HR}$ & $(95 \% \mathrm{Cl})$ & \\
\hline \multirow[t]{2}{*}{ Conditioning } & $\mathrm{CY} / \mathrm{TBI}$ & \multicolumn{2}{|c|}{ (Reference) } & \\
\hline & $\mathrm{HDCA} / \mathrm{CY} / \mathrm{TBI}$ & 1.50 & $(1.29-1.74)$ & $<0.01^{*}$ \\
\hline \multicolumn{5}{|l|}{ Other variables } \\
\hline \multirow[t]{2}{*}{ Sex } & Female & \multicolumn{2}{|c|}{ (Reference) } & \\
\hline & Male & 1.00 & $(0.88-1.14)$ & 0.96 \\
\hline \multirow[t]{2}{*}{ Age } & $\leq 49$ & \multicolumn{2}{|c|}{ (Reference) } & \\
\hline & $\geq 50$ & 1.93 & $(1.65-2.25)$ & $<0.01^{*}$ \\
\hline \multirow[t]{2}{*}{ PS } & $0-1$ & \multicolumn{2}{|c|}{ (Reference) } & \\
\hline & $\geq 2$ & 2.20 & $(1.74-2.80)$ & $<0.01^{*}$ \\
\hline \multirow[t]{2}{*}{$\mathrm{HCT}-\mathrm{Cl}$} & $\leq 2$ & \multicolumn{2}{|c|}{ (Reference) } & \\
\hline & $\geq 3$ & 1.90 & $(1.46-2.47)$ & $<0.01^{*}$ \\
\hline \multirow[t]{2}{*}{ CMV sero-status } & Negative & \multicolumn{2}{|c|}{ (Reference) } & \\
\hline & Positive & 1.24 & $(1.04-1.48)$ & $0.02^{*}$ \\
\hline \multirow[t]{2}{*}{ Diagnosis } & $\mathrm{AML}$ & \multicolumn{2}{|c|}{ (Reference) } & \\
\hline & MDS & 0.61 & $(0.49-0.75)$ & $<0.01^{*}$ \\
\hline \multirow[t]{2}{*}{ Disease risk } & Standard & \multicolumn{2}{|c|}{ (Reference) } & \\
\hline & High & 2.38 & $(2.10-2.71)$ & $<0.01^{*}$ \\
\hline \multirow[t]{2}{*}{ Days from diagnosis to $\mathrm{HCT}$} & $\leq 240$ & \multicolumn{2}{|c|}{ (Reference) } & \\
\hline & $\geq 241$ & 0.89 & $(0.78-1.01)$ & 0.08 \\
\hline \multirow[t]{3}{*}{ Donor } & Rel-BM & \multicolumn{2}{|c|}{ (Reference) } & \\
\hline & Rel-PB & 1.16 & $(0.96-1.40)$ & 0.13 \\
\hline & UR-BM & 1.11 & $(0.95-1.31)$ & 0.20 \\
\hline \multirow[t]{2}{*}{ HLA mismatch } & Matched & \multicolumn{2}{|c|}{ (Reference) } & \\
\hline & Mismatched & 1.25 & $(1.01-1.43)$ & $<0.01^{*}$ \\
\hline \multirow[t]{3}{*}{ Sex mismatch } & Matched & \multicolumn{2}{|c|}{ (Reference) } & \\
\hline & $\mathrm{M}$ to $\mathrm{F}$ & 1.04 & $(0.89-1.22)$ & 0.60 \\
\hline & $\mathrm{F}$ to $\mathrm{M}$ & 1.16 & $(0.99-1.36)$ & 0.07 \\
\hline $\mathrm{ABO}$ mismatch & Matched & (Refer & ence) & \\
\hline & Minor & 0.90 & $(0.75-1.07)$ & 0.23 \\
\hline & Major & 1.11 & $(0.93-1.32)$ & 0.23 \\
\hline & Both & 0.83 & $(0.64-1.07)$ & 0.15 \\
\hline GVHD prophylaxis & CyA based & (Refer & ence) & \\
\hline & Tac based & 1.01 & $(0.89-1.15)$ & 0.87 \\
\hline Year of HCT & $\leq 2008$ & (Refer & ence) & \\
\hline & $\geq 2009$ & 0.86 & $(0.75-0.99)$ & $0.04^{*}$ \\
\hline
\end{tabular}

Other abbreviations are explained in Table 1

$H R$ hazard ratio, $\mathrm{Cl}$ confidence interval

*Indicates statistically significant

37.5 vs $37.7 \%$, respectively) (Fig. 2). Hemorrhagic cystitis, mostly due to viral reactivation or infection [11], and thrombotic microangiopathy (TMA) were more frequently observed in the HDCA/CY/TBI group (HR, 1.47; $p=0.06$, and HR, 1.60; $p=0.04$, respectively). These two 
Table 3 Multivariate analysis of prognosis in patients with HDCA/CY/TBI compared with CY/TBI

\begin{tabular}{|c|c|c|c|c|c|c|c|c|c|c|}
\hline \multirow[t]{2}{*}{ Variables } & & \multicolumn{2}{|c|}{ Overall mortality } & \multirow[b]{2}{*}{$p$} & \multicolumn{2}{|c|}{ Tumor-related mortality } & \multirow[b]{2}{*}{$p$} & \multicolumn{2}{|l|}{ NRM } & \multirow[b]{2}{*}{$p$} \\
\hline & & $\mathrm{HR}$ & $(95 \% \mathrm{Cl})$ & & $\mathrm{HR}$ & $(95 \% \mathrm{Cl})$ & & $\mathrm{HR}$ & $(95 \% \mathrm{Cl})$ & \\
\hline \multirow[t]{2}{*}{ Conditioning } & $\mathrm{CY} / \mathrm{TBI}$ & \multicolumn{2}{|c|}{ (Reference) } & & \multicolumn{2}{|c|}{ (Reference) } & \multicolumn{4}{|c|}{ (Reference) } \\
\hline & HDCA/CY/TBI & 1.14 & $(0.96-1.34)$ & 0.13 & 0.90 & $(0.72-1.12)$ & 0.34 & 1.48 & $(1.15-1.91)$ & $<0.01^{*}$ \\
\hline \multicolumn{11}{|l|}{ Other variables } \\
\hline \multirow[t]{2}{*}{ Age } & $\leq 49$ & \multicolumn{2}{|c|}{ (Reference) } & & \multicolumn{2}{|c|}{ (Reference) } & \multicolumn{4}{|c|}{ (Reference) } \\
\hline & $\geq 50$ & 1.86 & $(1.57-2.20)$ & $<0.01^{*}$ & 1.31 & $(1.02-1.68)$ & $0.03^{*}$ & 2.04 & $(1.60-2.61)$ & $<0.01^{*}$ \\
\hline \multirow[t]{2}{*}{ PS } & $0-1$ & \multicolumn{2}{|c|}{ (Reference) } & & \multicolumn{2}{|c|}{ (Reference) } & \multicolumn{4}{|c|}{ (Reference) } \\
\hline & $\geq 2$ & 1.42 & $(1.09-1.85)$ & $<0.01^{*}$ & 1.73 & $(1.25-2.39)$ & $<0.01^{*}$ & 0.71 & $(0.41-1.23)$ & 0.22 \\
\hline \multirow[t]{2}{*}{ CMV sero-status } & Negative & \multicolumn{2}{|c|}{ (Reference) } & & \multicolumn{2}{|c|}{ (Reference) } & \multicolumn{4}{|c|}{ (Reference) } \\
\hline & Positive & 1.12 & $(0.93-1.34)$ & 0.23 & 1.29 & $(1.00-1.65)$ & $0.05^{*}$ & 0.91 & $(0.70-1.18)$ & 0.47 \\
\hline \multirow[t]{2}{*}{ Diagnosis } & $\mathrm{AML}$ & \multicolumn{2}{|c|}{ (Reference) } & & \multicolumn{2}{|c|}{ (Reference) } & \multicolumn{4}{|c|}{ (Reference) } \\
\hline & MDS & 0.40 & $(0.32-0.51)$ & $<0.01^{*}$ & 0.18 & $(0.12-0.27)$ & $<0.01^{*}$ & 1.18 & $(0.87-1.59)$ & 0.28 \\
\hline \multirow[t]{2}{*}{ Disease risk } & Standard & \multicolumn{2}{|c|}{ (Reference) } & & \multicolumn{2}{|c|}{ (Reference) } & \multicolumn{4}{|c|}{ (Reference) } \\
\hline & High & 2.53 & $(2.18-2.93)$ & $<0.01^{*}$ & 3.98 & $(3.26-4.85)$ & $<0.01^{*}$ & 0.97 & $(0.77-1.23)$ & 0.82 \\
\hline Days from diagnosis to $\mathrm{HCT}$ & $\leq 240$ & & ference) & & & erence) & & & ference) & \\
\hline & $\geq 241$ & 0.88 & $(0.76-1.01)$ & 0.07 & 0.80 & $(0.66-0.97)$ & $0.02^{*}$ & 0.98 & $(0.79-1.22)$ & 0.89 \\
\hline HLA mismatch & Matched & & ference) & & & erence) & & & ference) & \\
\hline & Mismatched & 1.25 & $(1.08-1.44)$ & $<0.01^{*}$ & 0.90 & $(0.73-1.10)$ & 0.30 & 1.60 & $(1.29-1.99)$ & $<0.01^{*}$ \\
\hline Sex mismatch & Matched & & ference) & & & erence) & & & ference) & \\
\hline & $M$ to $F$ & 0.97 & $(0.81-1.15)$ & 0.70 & 0.91 & $(0.72-1.15)$ & 0.44 & 1.01 & $(0.77-1.31)$ & 0.97 \\
\hline & $\mathrm{F}$ to $\mathrm{M}$ & 1.12 & $(0.94-1.33)$ & 0.20 & 0.94 & $(0.74-1.20)$ & 0.63 & 1.28 & $(0.99-1.65)$ & 0.07 \\
\hline Year of HCT & $\leq 2008$ & & ference) & & & erence) & & & ference) & \\
\hline & $\geq 2009$ & 0.89 & $(0.77-1.02)$ & 0.10 & 0.96 & $(0.80-1.16)$ & 0.70 & 0.76 & $(0.61-0.94)$ & $0.01^{*}$ \\
\hline
\end{tabular}

Other abbreviations are explained in Tables 1 and 2

NRM non-relapse mortality

*Indicates statistically significant

complications were related to a significantly higher proportion of NRM (data not shown). Other potential complications of HDCA, such as central nervous system (CNS) dysfunction and acute respiratory dysfunction syndrome (ARDS) [12], were not increased in the HDCA/ CY/TBI group.

\section{Discussion}

In this study on myeloablative BMT/PBSCT for AML/ MDS, we did not observe the improvement of OS in the HDCA/CY/TBI group due to (1) a higher proportion of NRM and (2) the lack of apparent additional anti-leukemic effect of HDCA. These results differ from those of CBT, in which a stronger anti-leukemic effect without increased NRM led to superior OS in HDCA/CY/TBI [5].

Among acute phase complications that can lead to NRM, hemorrhagic cystitis and TMA were increased after HDCA/CY/TBI. These complications, if not resolved early, can induce renal failure, prohibit immune reconstitution, and deteriorate patient's nutrition and performance status, which may ultimately lead to significantly higher NRM $[11,13]$. The strong cytotoxicity of HDCA combined with significantly poorer neutrophil engraftment might cause cystitis-related virus reactivation or vascular endothelial cell injury which can induce hemorrhagic cystitis or TMA. These features were not observed in CBT [5]; the relatively higher incidence of acute GVHD in BMT/PBSCT can explain this difference because both hemorrhagic cystitis and TMA are closely related to preceding acute GVHD $[11,13]$.

On the other hand, no additional anti-leukemic effect of HDCA was apparent in this study. HDCA can reduce the remaining leukemia cells that may cause relapse after HCT [12]. This anti-leukemic effect of HDCA directly reduced the incidence of relapse in CBT [5] because graft-versus-leukemia (GVL) effects after CBT was relatively weak [14]; relapse after CBT mainly depends on the efficacy of conditioning regimens [5]. In BMT/ PBSCT, however, GVL effects are much stronger than CBT especially in the case of HLA-mismatched transplantation [14]. Suppression of total relapse after HCT is mainly attributed to continuous GVL effects [14] 
Table 4 Causes of NRM

\begin{tabular}{|c|c|c|c|c|c|c|c|}
\hline \multirow[t]{2}{*}{ Cause of NRM } & \multicolumn{2}{|c|}{ Total } & \multicolumn{2}{|c|}{$\mathrm{CY} / \mathrm{TBI}$} & \multicolumn{2}{|c|}{$\mathrm{HDCA} / \mathrm{CY} / \mathrm{TBI}$} & \multirow[b]{2}{*}{$p$} \\
\hline & $N$ & $\%$ & $N$ & $\%$ & $N$ & $\%$ & \\
\hline Infection & 110 & 27.3 & 78 & 26.4 & 32 & 29.6 & 0.52 \\
\hline Bacteria & 61 & & 43 & & 18 & & \\
\hline Virus & 19 & & 14 & & 5 & & \\
\hline Fungi & 13 & & 9 & & 4 & & \\
\hline Rejection/engraftment failure & 3 & 0.7 & 3 & 1.0 & 0 & 0.0 & 0.29 \\
\hline TMA & 10 & 2.5 & 8 & 2.7 & 2 & 1.9 & 0.62 \\
\hline VOD & 15 & 3.7 & 12 & 4.1 & 3 & 2.8 & 0.54 \\
\hline GVHD & 44 & 10.9 & 32 & 10.8 & 12 & 11.1 & 0.94 \\
\hline Acute & 20 & & 14 & & 6 & & \\
\hline Chronic & 24 & & 18 & & 6 & & \\
\hline Hemorrhage & 24 & 6.0 & 18 & 6.1 & 6 & 5.6 & 0.84 \\
\hline Organ failure & 127 & 31.5 & 95 & 32.2 & 32 & 29.6 & 0.62 \\
\hline Liver & 9 & & 7 & & 2 & & \\
\hline Heart & 13 & & 8 & & 5 & & \\
\hline Kidney & 6 & & 4 & & 2 & & \\
\hline CNS & 8 & & 6 & & 2 & & \\
\hline Lung & 82 & & 62 & & 20 & & \\
\hline Interstitial pneumonia & 40 & & 29 & & 11 & & \\
\hline ARDS & 14 & & 13 & & 1 & & \\
\hline Secondary malignancy & 1 & 0.2 & 1 & 0.3 & 0 & 0.0 & 0.54 \\
\hline Others & 69 & 17.1 & 48 & 16.3 & 21 & 19.4 & \\
\hline Total & 403 & 100.0 & 295 & 100.0 & 108 & 100.0 & \\
\hline
\end{tabular}

Other abbreviations are explained in Tables 1-3

TMA thrombotic microangiopathy, VOD veno-occlusive disease, CNS central nervous system, ARDS acute respiratory distress syndrome

compared to the conditioning regimens which will be inactivated rapidly after HCT [12]; strength of conditioning regimens (for example, HDCA addition in this study) may not directly influence on relapse reduction. These differences in GVL effects can partly explain the discrepancy in the efficacy of HDCA on post-transplant relapse or disease-related death.

A larger proportion of patients with high-risk disease and worse performance status in the HDCA/CY/TBI group may confound the outcomes, but multivariate and subgroup analyses indicated unimproved prognosis in HDCA/CY/TBI even after eliminating those confounding factors. Moreover, subgroup analyses regarding the percentage of myeloblast just before conditioning regimens were carried out; no significant differences of OS between $\mathrm{CY} / \mathrm{TBI}$ and HDCA/CY/TBI were found in any subgroups (data not shown). The bias in regard to the HCT centers, however, still remains to be overcome in this study. The choice of conditioning regimen depends on the attending physicians in each institution, indicating that the clinical experiences of each transplant center can

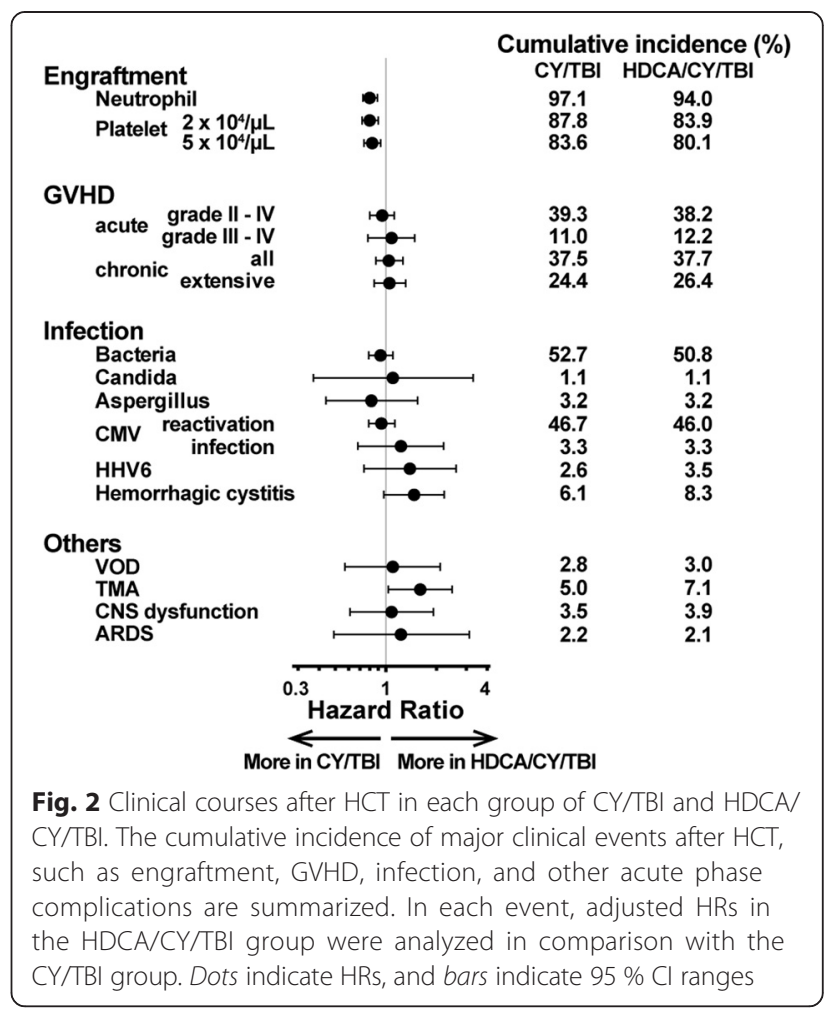

be a confounding factor. Unfortunately, we were not able to adjust this factor because the database did not contain such information.

The combination of granulocyte colony stimulating factor (G-CSF) with HDCA is another important topic; it is reported that G-CSF-combined HDCA/CY/TBI provided low NRM and high OS in a previous study [15]. In our cohort, patients with G-CSF-combined HDCA/CY/ TBI regimen $(N=25)$ revealed almost the same prognosis (HR, 1.02; $95 \% \mathrm{CI}, 0.59-1.76 ; p=0.95)$ as HDCA/ CY/TBI without G-CSF.

In summary, this study showed the inefficacy of adding HDCA to CY/TBI in BMT/PBSCT for AML/MDS, suggesting that the merits of HDCA in CBT cannot be extrapolated to $\mathrm{BMT} / \mathrm{PBSCT}$. Incidence of $\mathrm{GVHD}$ or strength of GVL effects may be related to these differences between donor sources. This single-country retrospective analysis should be validated in future prospective studies in order to determine proper conditioning regimens in BMT/PBSCT for AML/MDS.

\section{Additional file}

Additional file 1: Figure S1. Subgroup analyses of OS with respect to patient characteristics. OS was compared in each subgroup with respect to patient characteristics. The adjusted HRs of overall mortality in the HDCA/CY/TBI group were shown compared to the CY/TBI group. Black dots indicate $\mathrm{HRs}$, and $95 \% \mathrm{Cl}$ ranges are shown by black bars. 


\section{Abbreviations}

AML: acute myelogenous leukemia; BMT: bone marrow transplantation; CBT: cord blood transplantation; Cl: confidence interval; $\mathrm{CY}$ : cyclophosphamide; GVHD: graft-versus-host disease; GVL: graft versus leukemia; HCT: hematopoietic cell transplantation; HDCA: high-dose cytarabine; HLA: human leukocyte antigen; HR: hazard ratio; MDS: myelodysplastic syndrome; NRM: non-relapse mortality; OS: overall survival; PBSCT: peripheral blood stem cell transplantation; Rel: related donor; TBI: total-body irradiation; TMA: thrombotic microangiopathy; UR: unrelated donor.

\section{Competing interests}

The authors declare that they have no competing interests.

\section{Authors' contributions}

YArai designed the study, reviewed and analyzed data, and wrote the paper. $K A, J T, T K$, and AT interpreted data and revised the manuscript. TE, SO, HH, $\mathrm{TF}, \mathrm{YO}, \mathrm{YK}, \mathrm{CK}, \mathrm{MK}, \mathrm{KI}, \mathrm{MO}, \mathrm{TI}$, and YAtsuta contributed to the data collection and provided critique to the manuscript. All authors read and approved the final manuscript.

\section{Acknowledgements}

The authors would like to thank all the physicians and data managers at the centers who contributed valuable data on transplantation to the Japan Society for Hematopoietic Cell Transplantation (JSHCT). We also thank the members of the Data Management Committees of JSHCT. This study was supported by research funding from the Ministry of Education, Science, Sports, and Culture in Japan to TK

\section{Author details}

${ }^{1}$ Department of Hematology and Oncology, Graduate School of Medicine, Kyoto University, 54, Shogoin Kawahara-cho, Sakyo-ku, Kyoto 606-8507, Japan. ${ }^{2}$ Department of Hematology, Hamanomachi Hospital, Fukuoka, Japan. ${ }^{3}$ Department of Hematology, Sapporo Hokuyu Hospital, Sapporo, Japan. ${ }^{4}$ Department of Hematology/Division of Stem Cell Transplantation, Kobe General Hospital/Institute of Biomedical Research and Innovation, Kobe, Japan. ${ }^{5}$ Department of Hematopoietic Stem Cell Transplantation, National Cancer Center Hospital, Tokyo, Japan. 'Department of Hematology, Japanese Red Cross Nagoya First Hospital, Nagoya, Japan. ${ }^{7}$ Division of Hematology, Saitama Medical Center, Jichi Medical University, Saitama, Japan.

${ }^{8}$ Department of Hematology, Meitetsu Hospital, Nagoya, Japan. ${ }^{9}$ Department of Cell Therapy and Transplantation Medicine, the University of Tokyo Hospital, Tokyo, Japan. ${ }^{10}$ Department of Hematology, Hiroshima Red Cross Hospital \& Atomic-bomb Survivors Hospital, Hiroshima, Japan. ${ }^{11}$ Department of Hematology/Oncology, Tokai University School of Medicine, Isehara, Japan. ${ }^{12}$ Department of Hematology and Oncology, Hiroshima University Hospital, Hiroshima, Japan. ${ }^{13}$ Japanese Data Center for Hematopoietic Cell Transplantation, Nagoya, Japan. ${ }^{14}$ Department of Healthcare Administration, Nagoya University Graduate School of Medicine, Nagoya, Japan.

${ }^{15}$ Department of Internal Medicine Division of Hematology, Aichi Medical University, Nagakute, Japan.

Received: 28 July 2015 Accepted: 27 August 2015

Published online: 04 September 2015

\section{References}

1. Duval M, Klein JP, He W, Cahn JY, Cairo M, Camitta BM, et al. Hematopoietic stem-cell transplantation for acute leukemia in relapse or primary induction failure. J Clin Oncol. 2010;28:3730-8.

2. Nagler A, Rocha V, Labopin M, Unal A, Ben Othman T, Campos A, et al. Allogeneic hematopoietic stem-cell transplantation for acute myeloid leukemia in remission: comparison of intravenous busulfan plus cyclophosphamide (Cy) versus total-body irradiation plus Cy as conditioning regimen-a report from the acute leukemia working party of the European group for blood and marrow transplantation. J Clin Oncol. 2013;31:3549-56.

3. Copelan EA, Hamilton BK, Avalos B, Ahn KW, Bolwell BJ, Zhu X, et al. Better leukemia-free and overall survival in $A M L$ in first remission following cyclophosphamide in combination with busulfan compared with TBI. Blood. 2013;122:3863-70.
4. Magenau J, Couriel DR. Hematopoietic stem cell transplantation for acute myeloid leukemia: to whom, when, and how. Curr Oncol Rep. 2013;15:436-44.

5. Arai Y, Takeda J, Aoki K, Kondo T, Takahashi S, Onishi Y, et al. Efficiency of high-dose cytarabine added to CY/TBI in cord blood transplantation for myeloid malignancy. Blood. 2015;126:415-22.

6. Inamoto $Y$, Nishida T, Suzuki R, Miyamura K, Sao H, lida H, et al. Significance of additional high-dose cytarabine in combination with cyclophosphamide plus total body irradiation regimen for allogeneic stem cell transplantation. Bone Marrow Transplant. 2007;39:25-30.

7. Kanda Y, Sakamaki H, Sao H, Okamoto S, Kodera Y, Tanosaki R, et al. Effect of conditioning regimen on the outcome of bone marrow transplantation from an unrelated donor. Biol Blood Marrow Transplant. 2005;11:881-9.

8. Atsuta Y, Suzuki R, Yoshimi A, Gondo H, Tanaka J, Hiraoka A, et al. Unification of hematopoietic stem cell transplantation registries in Japan and establishment of the TRUMP System. Int J Hematol. 2007;86:269-74.

9. Ho VT, Kim HT, Aldridge J, Liney D, Kao G, Armand P, et al. Use of matched unrelated donors compared with matched related donors is associated with lower relapse and superior progression-free survival after reduced-intensity conditioning hematopoietic stem cell transplantation. Biol Blood Marrow Transplant. 2011;17:1196-204.

10. Kanda J, Saji H, Fukuda T, Kobayashi T, Miyamura K, Eto T, et al. Related transplantation with $\mathrm{HLA}-1 \mathrm{Ag}$ mismatch in the GVH direction and HLA-8/8 allele-matched unrelated transplantation: a nationwide retrospective study. Blood. 2012;119:2409-16.

11. Arai Y, Maeda T, Sugiura H, Matsui H, Jo T, Ueda T, et al. Risk factors for and prognosis of hemorrhagic cystitis after allogeneic stem cell transplantation: retrospective analysis in a single institution. Hematology. 2012;17:207-14.

12. Reese ND, Schiller GJ. High-dose cytarabine $(\mathrm{HD}$ araC) in the treatment of leukemias: a review. Curr Hematol Malig Rep. 2013;8:141-8.

13. Arai Y, Yamashita K, Mizugishi K, Watanabe T, Sakamoto S, Kitano T, et al. Serum neutrophil extracellular trap levels predict thrombotic microangiopathy after allogeneic stem cell transplantation. Biol Blood Marrow Transplant. 2013;19:1683-9.

14. van Besien K. Allogeneic transplantation for AML and MDS: GVL versus GVHD and disease recurrence. Hematology Am Soc Hematol Educ Program. 2013;2013:56-62.

15. Konuma T, Kato S, Ishii H, Oiwa-Monna M, Asano S, Tojo A, et al. Long-term outcomes of granulocyte colony-stimulating factor-combined conditioning in allogeneic hematopoietic stem cell transplantation from HLA-identical family donors for myeloid malignancies. Leuk Res. 2015;39:625-31.

\section{Submit your next manuscript to BioMed Central and take full advantage of:}

- Convenient online submission

- Thorough peer review

- No space constraints or color figure charges

- Immediate publication on acceptance

- Inclusion in PubMed, CAS, Scopus and Google Scholar

- Research which is freely available for redistribution 